\title{
A $10 \mathrm{~kb}$ nucleotide sequence at the $5^{\prime}$ flanking region $\left(32^{\circ}\right)$ of srfAA of the Bacillus subtilis chromosome
}

\author{
Yoshiyuki Fujishima and Kunio Yamane
}

Author for correspondence: Kunio Yamane. Tel./Fax: +81298536680.

Institute of Biological Sciences, University of Tsukuba, Tsukuba-shi, Ibaraki 305, Japan

\begin{abstract}
The nucleotide sequence of approximately $10 \mathrm{~kb}$ at the $5^{\prime}$ flanking region (32') of srfAA of the Bacillus subtilis chromosome was determined. Eleven putative ORFs were identified. Three of them (orf6, orf7 and orf8) coincided with known $B$. subtilis genes (coms, coml and t/pC) encoding a competence-specific protein, a DNA-entry nuclease and a transducer-like protein, respectively. The products of two other ORFs showed similarity to GInP of Escherichia coli (orf1) and $\beta$-glucosidase A of B. polymyxa (orf5).
\end{abstract}

Keywords: Bacillus subtilis, genome sequencing, $32^{\circ}$ region, $\operatorname{srf} A A$

\section{INTRODUCTION}

In a previous paper (Fuma et al., 1993) we reported the isolation of four independent clones that hybridized to the NotI linking plasmids pNEXT13 and pNEXT61 (Itaya \& Tanaka, 1991). Nucleotide sequence analysis revealed that they contained $\operatorname{srf} A A$ and $\operatorname{srf} A B$ (Cosmina et al., 1993). One of these, clone 110 , hybridized with pNEXT13 only and it contained an approximately $10 \mathrm{~kb}$ DNA segment at the $5^{\prime}$ flanking region of $\operatorname{srf} A A$. We have now sequenced and analysed this segment.

Clone 110 was obtained from a $\lambda$ DASH II library of Bacillus subtilis chromosomal DNA partially digested with Sau3AI (provided by N. Ogasawara) using ${ }^{32} \mathrm{P}$-labelled pNEXT13 as a probe. All sequences were determined using a 373A DNA sequencer from Applied Biosystems using the Taq Dye Primer Cycle Sequencing Kit and the Taq DyeDeoxy Terminator Cycle Sequencing Kit after preparing randomly overlapping libraries for the shotgun sequencing method as described by Ogawa et al. (1995). The compiled sequences were analysed for the location of possible ORFs using GENETYX-MAC from Software Development (Tokyo). The amino acid sequences of the products of each ORF were searched for similarity to sequences reported previously in non-redundant protein sequence data banks using FASTA and BLAST e-mail servers in the Human Genome Center, Institute of Medical Science, University of Tokyo.

Abbreviation: SD, Shine-Dalgarno.

The GSDB/EMBLDDBJ/NCBI accession number of the nucleotide sequence reported in this paper is $\mathrm{D} 30762$.
Putative ORFs in the region sequenced were searched in all six possible translation frames. Based on the length of the ORF starting from ATG, GTG or TTG and preceded by a Shine-Dalgarno (SD) sequence, 11 putative ORFs were detected (Fig. 1 and Table 1). The initiation codon for 9 ORFs was ATG, but TTG for orfo and GTG for orf11. The direction of transcription and translation of orf $3,4,5,11$ and $\operatorname{srf} A A$ was the same as that of DNA replication, whereas that of the other ORFs (orf1, 2, 6, 7, 8, 9 and 10) was in the opposite direction.

Comparison of the amino acid sequences of the putative products of each ORF with the non-redundant protein sequence data banks revealed that the nucleotide sequences of orf6, orf 7 and orf 8 and their predicted amino acid sequences have been reported and characterized genetically and biochemically (Vosman et al., 1988;

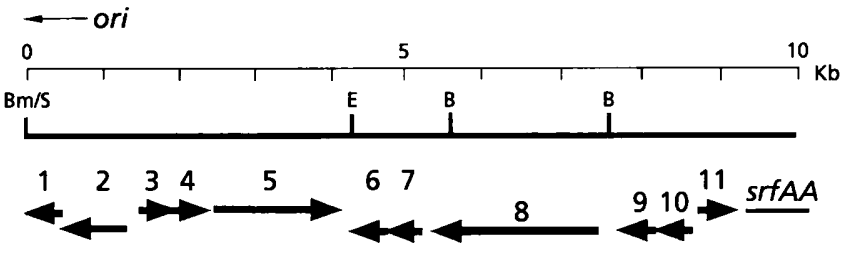

Fig. 1. Organization of ORFs of the B. subtilis chromosome $32^{\circ}$ area at the $5^{\prime}$ flanking region of srfAA. The scale (in kb) starts at the $\mathrm{G}$ residue at the $\mathrm{BamHI} / \mathrm{Sau} 3 \mathrm{Al}$ junction site $(\mathrm{Bm} / \mathrm{S})$. EcoRI (E) and Bg/lI (B) sites are indicated. ORFs are shown by thick black arrows and the arrowheads show the direction of their transcription and translation. Numbers on the arrows indicate each ORF. 
Table 1. Putative ORFs in the $10 \mathrm{~kb}$ sequence at the $5^{\prime}$ flanking region of $\operatorname{sfAA}\left(32^{\circ}\right)$

\begin{tabular}{|llcl|}
\hline ORF & $\begin{array}{c}\text { Endpoints } \\
\text { (nucleotides) }\end{array}$ & $\begin{array}{c}\text { Size of product } \\
\mathbf{( a a / k D a )}\end{array}$ & $\begin{array}{c}\text { SD consensus sequence (upper case) } \\
\text { and initiation codon (bold) }\end{array}$ \\
\hline orf1 & $152<829$ & $226 / 25 \cdot 2$ & AGGAcGTtGAtttgtaatcggacgccatg \\
orf2 & $842<1408$ & $189 / 21 \cdot 0$ & AAgGAGaTGggcsattgacgggatg \\
orf3 & $2207>2533$ & $109 / 12 \cdot 2$ & AGGAaaGAcccaacgacagcatg \\
orf4 & $2618>2947$ & $110 / 12 \cdot 8$ & GGAGGaataaaatggatg \\
orf5 & $3104>4534$ & $477 / 55 \cdot 1$ & AGGAGtgataaacactatg \\
orf6 & $4577<4972$ & $132 / 15 \cdot 0$ & AgAGGAGGaacagcacattg \\
orf7 & $5002<5310$ & $103 / 11 \cdot 5$ & AAAGaAtatgataaacaatg \\
orf8 & $5619<7337$ & $573 / 61 \cdot 8$ & agGGAGGaattatg \\
orf9 & $7700<8005$ & $102 / 11 \cdot 1$ & AAGGAtaactccgatg \\
orf10 & $8118<8642$ & $175 / 19 \cdot 0$ & AAGGgaGTGgatcaacaatg \\
orf11 & $8928>9233$ & $102 / 12 \cdot 0$ & AGaAGGaattaacgcttcagtg \\
srf $A A$ & $9810>$ & - & GGAGGtatgacaatatg \\
\hline
\end{tabular}

Table 2. Similarity of predicted ORF products to known proteins

\begin{tabular}{|c|c|c|c|}
\hline Product & Similar protein in database & Identity observed & $\begin{array}{l}\text { BLAST } \\
\text { score }\end{array}$ \\
\hline \multirow[t]{3}{*}{ Orf1 } & Glutamine permease operon GlnP protein in E. coli & $39 \%$ in the $\mathrm{C}$-terminal half & 209 \\
\hline & Histidine permease membrane $\mathrm{M}$ protein (HisM) of E. coli & $33 \%$ in the $\mathrm{C}$-terminal region & 190 \\
\hline & $\begin{array}{l}\text { Arginine periplasmic transport system protein ArtQ in } \\
\text { E. coli }\end{array}$ & $36 \%$ in the C-terminal half & 177 \\
\hline \multirow[t]{2}{*}{ Orf5 } & $\beta$-Glucosidase A of B. polymyxa & $57 \%$ in the $\mathrm{N}$-terminal 135 residues & 457 \\
\hline & $\beta$-Glucosidase $A$ of $B$. circulans & $61 \%$ in the $\mathrm{N}$-terminal 128 residues & 457 \\
\hline Orf6 & Competence specific protein of B. subtilis & $100 \%$ for the entire length & 688 \\
\hline Orf7 & DNA-entry nuclease of $B$. subtilis & $73 \%$ in 103 residues & 406 \\
\hline Orf8 & $\begin{array}{l}\text { Transducer-like protein of B. subtilis homologous } \\
\text { to methyl-accepting protein of E. coli }\end{array}$ & $100 \%$ for the entire length & - \\
\hline
\end{tabular}

Hanlon et al., 1994); the functions of the products of two other ORFs (Orf1 and Orf5) were predicted on the basis of a considerable degree of similarity to known protein sequences from other bacteria (Table 2). The amino acid sequence of Orf1 showed considerable similarity $(39 \%$, $33 \%$ and $36 \%$ identity, respectively) to the C-terminal regions of $\mathrm{Gln} P$ (219 residues) of the glutamine permease operon (Nohno et al., 1986), histidine permease membrane M protein (HisM, 144 residues; Kraft \& Leinwand, 1987) and arginine periplasmic transport system protein (ArtQ, 239 residues; Wissenbach \& Unden, 1993) of Escherichia coli. However, the sequence of Orf1 did not show any similarity to those of B. subtilis GntP and lysine-specific permease of $E$. coli. Since orf 2 does not have a clear promoter sequence, and $g \ln H, g \ln P$ and $g \ln Q$ are included in an operon in E. coli, orf 1 and orf 2 seemed to comprise at least part of an operon. However, the amino acid sequence of Orf2 showed no similarity to $\mathrm{G} \ln H$ or $\mathrm{G} \ln Q$, so this is probably not the case. Orf1 may be a member of a permease family. The orf 5 product shows $61 \%, 57 \%$, $65 \%$ and $58 \%$ amino acid sequence identity with $\beta$ glucosidase A from $B$. circulans (450 residues; Paavilainen et al., 1993), B. polymyxa (448 residues; Gonzalez-Candelas et al., 1990), Caldocellum saccharolyticum (455 residues; Love \& Bergquist, 1988) and Clostridium thermocellum (448 residues; Graebnitz et al., 1991), respectively. This implies that Orf5 is the B. subtilis $\beta$-glucosidase.

The nucleotide sequences of orf 6 and $\operatorname{orf} 7$ were the same as those reported by Vosman et al. (1988) except for one additional $G$ residue in orf 7 at nucleotide position 5086 . This addition resulted in a frameshift in orf 7 and consequently Orf7, corresponding to comI encoding a DNA-entry nuclease, was found to be only 103 amino acids $(11.5 \mathrm{kDa})$ not 144 amino acids $(17 \mathrm{kDa})$ as previously reported (Vosman et al., 1988). orf6 corresponds to comJ encoding a competence-specific protein and its amino acid sequence was completely identical to that in the previous report. The reading frame of orf 7 did not overlap with that of orf6. The nucleotide and amino acid sequences of Orf8 were the same as those reported by Hanlon et al. (1994). The functions of the other ORFs (Orf2, 3, 4, 9, 10 and 11) remain unknown.

The other two possible ORFs (5837-6292 and 9003-9462) would be transcribed in the opposite direction to, and are located within the orf 8 and orf11 regions, respectively. 
They did not exhibit sufficient consensus SD sequences and were not studied.

\section{ACKNOWLEDGEMENTS}

We thank Dr M. Itaya and Dr N. Ogasawara for pNEXT13, a Not I linking clone and the $\lambda$ DASH II library of $B$. subtilis chromosomal DNA. This work was supported by a Grant-inAid for Creative Research (Human Genome Project) from the Ministry of Education, Science and Culture of Japan.

\section{REFERENCES}

Cosmina, P., Rodriguez, F., de Ferra, F., Grandi, G., Perego, M., Venema, G. \& van Sinderen, D. (1993). Sequence and analysis of the genetic locus responsible for surfactin synthesis in Bacillus subtilis. Mol Microbiol 8, 821-831.

Fuma, S., Fujishima, Y., Corbell, N., D'Souza, C., Nakano, M. M., Zuber, P. \& Yamane, K. (1993). Nucleotide sequence of $5^{\prime}$ portion of $\operatorname{srf} A$ that contains the region required for competence establishment in Bacillus subtilis. Nucleic Acids Res 21, 93-97.

Gonzalez-Candelas, L., Ramon, D. \& Polaina, J. (1990). Sequence and homology analysis of two genes encoding $\beta$-glucosidases from Bacillus polymyxa. Gene 95, 31-38.

Graebnitz, F., Seiss, M., Ruecknogel, K. P. \& Staudenbauer, W. L. (1991). Structure of the $\beta$-glucosidase A gene $\mathrm{bgl} A$ of $C$ lostridium thermocellum: sequence analysis reveals a superfamily of cellulases and $\beta$-glucosidases including human lactase/phlorizin hydrolase. Eur J Biochem 200, 301-309.

Hanlon, D. W., Rosardo, M. M. L., Ordal, G. W., Venema, G. \& Van Sinderen, D. (1994). Identification of TlpC, a novel $62 \mathrm{kDa}$ MCP-like protein from Bacillus subtilis. Microbiology 140, 1847-1854.
Itaya, M. \& Tanaka, T. (1991). Complete physical map of the Bacillus subtilis 168 chromosome constructed by a gene-directed mutagenesis method. J Mol Biol 220, 631-648.

Kraft, R. \& Leinwand, L. A. (1987). Sequence of the complete P protein gene and part of the $\mathrm{M}$ protein gene from the histidine transport operon of E. coli: compared to that of $S$. typhimurium. Nucleic Acids Res 15, 8568.

Love, D. R. \& Bergquist, P. L. (1988). Sequence structure and expression of a cloned $\beta$-glucosidase gene from an extreme thermophile. Mol \& Gen Genet 213, 84-92.

Nohno, T., Saito, T. \& Hong, J.-S. (1986). Cloning and complete nucleotide sequence of the Escherichia coli glutamine permease operon (glnHPQ). Mol \& Gen Genet 205, 260-269.

Ogawa, K., Akagawa, E., Nakamura, K. \& Yamane, K. (1995). Determination of a 21548 nucleotide sequence around the $24^{\circ}$ region of the Bacillus subtilis chromosome. Microbiology 141, 269-275.

Paavilainen, S. K., Hellman, J. \& Korpela, T. (1993). Purification, characterization, gene cloning and sequencing of a new $\beta$ glucosidase from Bacillus circulans subsp. alkalopbilus. Appl Environ Microbiol 59, 927-932.

Vosman, B., Kuiken, G., Kooistra, J. \& Venema, G. (1988). Transformation in Bacillus subtilis: involvement of the 17kilodalton DNA-entry nuclease and the competence-specific 18kilodalton protein. J Bacteriol 170, 3703-3710.

Wissenbach, U. \& Unden, G. (1993). Physical map location of the new artPIQMJ genes of Escherichia coli, encoding a periplasmic arginine transport system. $J$ Bacteriol 175, 3687-3688.

Received 13 July 1994; revised 20 September 1994; accepted 13 October 1994. 